\title{
Pediatric neurofibromatosis I and parental stress: a multicenter study
}

This article was published in the following Dove Press journal:

Neuropsychiatric Disease and Treatment

22 January 2014

Number of times this article has been viewed

\author{
Maria Esposito' \\ Rosa Marotta ${ }^{2}$ \\ Michele Roccella ${ }^{3}$ \\ Beatrice Gallai ${ }^{4}$ \\ Lucia Parisi ${ }^{3}$ \\ Serena Marianna Lavano ${ }^{2}$ \\ Marco Carotenuto' \\ 'Clinic of Child and Adolescent \\ Neuropsychiatry, Department of \\ Mental Health, Physical and Preventive \\ Medicine, Second University of \\ Naples, Naples, Italy; ${ }^{2}$ Department of \\ Psychiatry, “Magna Graecia” University \\ of Catanzaro, Catanzaro, Italy; ${ }^{3}$ Child \\ Neuropsychiatry, Department of \\ Psychology, University of Palermo, \\ Palermo, Italy; ${ }^{4}$ Unit of Child and \\ Adolescent Neuropsychiatry, \\ University of Perugia, Perugia, Italy
}

Correspondence: Marco Carotenuto Clinic of Child and Adolescent Neuropsychiatry, Department of Mental Health, Physical and Preventive Medicine, Via Sergio Pansini 5 PAD XI, 80I3I Naples, Italy

Tel +39815666988

Fax $+398 I 5666694$

Email marco.carotenuto@unina2.it
Background: Neurofibromatosis 1 (NF1) is a complex and multifaceted neurocutaneous syndrome with many and varied comorbidities. The literature about the prevalence and degree of maternal stress and the impact of NF1 in the parent-child interaction is still scant. The aim of this study was to evaluate the prevalence of maternal stress in a large pediatric sample of individuals affected by NF1.

Methods: Thirty-seven children (19 boys, 18 girls) of mean age 7.86 \pm 2.94 (range 5-11) years affected by typical NF1 and a control group comprising 405 typically developing children (207 boys, 198 girls; mean age $8.54 \pm 2.47$ years) were included in this study. To assess parental stress, the mothers of all individuals (NF1 and comparisons) filled out the Parenting Stress Index-Short Form test.

Results: The two study groups were comparable for age ( $P=0.116)$, gender $(P=0.886)$, and body mass index adjusted for age $(P=0.305)$. Mothers of children affected by NF1 reported higher mean Parenting Stress Index-Short Form scores on the Parental Distress domain $(P<0.001)$, Difficult Child domain $(P<0.001)$, and Total Stress domain than the mothers of typically developing children (controls) $(P<0.001)$. No significant differences between the two groups were found for the Parent-Child Dysfunctional Interaction domain $(P=0.566)$ or Defensive Responding domain scores $(P=0.160)$.

Conclusion: NF1 is considered a multisystemic and complex disease, with many still unrecognized features in pediatric patients and in their families. In this light, our findings about the higher levels of maternal stress highlight the importance of considering the environmental aspects of NF1 management in developmental age.

Keywords: children, Parental Stress Index, maternal stress, von Recklingausen disease

\section{Introduction}

Neurocutaneous syndromes are a group of genetic pathologies linked to the common alteration in development of neural crest. ${ }^{1}$ In general, the primary neurocutaneous syndromes are all very different diseases with different genetic mutations, but the unifying factor amongst them is that all are neurocristopathies and can be explained as such, including the tumor-suppressor function of several of these genes, especially those of neurofibromatosis 1 and 2 and tuberous sclerosis complex. ${ }^{1}$

NF1 (OMIM \#162200) ${ }^{2}$ was first described in 1882 by von Recklinghausen, and is among the most common autosomal dominant disorders, with a prevalence of one in 4,000 individuals worldwide, ${ }^{3,4}$ caused by the NF1 gene mutation coded by chromosome 17q11.2, with the subsequent alteration in Ras-mediated cell proliferation modulation..$^{5,6}$ 
Nervous system involvement in NF1 can cause learning disabilities; plexiform neurofibromas; megalencephaly; cerebral tumors; headache; acqueductal stenosis; cerebrovascular disease; meningoceles; neurofibromatous neuropathy; and cerebral high-signal lesions, visible on T2-weighted magnetic resonance images. ${ }^{7-10}$ The varied clinical NF1 manifestations could significantly impact family relationships, as described by Ablon in 2000, who, in 16 families studied, reported shock, upset, and subsequent depression as responses to NF1 diagnosis, ${ }^{11}$ pinpointing the relevance of the parents' emotional reactions in NF1 management. On the other hand, behavioral aspects and parental stress of children and adolescents with several disabling genetic and/or chronic conditions were previously described, ${ }^{12,13}$ and the role of parental stress in the management of childhood chronic illnesses ${ }^{14-17}$ was demonstrated.

To date, reports concerning the impact of neurocutaneous syndrome in parental stress management and parent-child interactions are scant. Therefore, the aim of the present study was to assess the maternal stress levels in a population of school-aged children affected by NF1.

\section{Materials and methods Study population}

The study population comprised 37 children (19 boys, 18 girls) of mean age 7.86 \pm 2.94 (range 5-11) years affected by typical NF1 and referred consecutively to the Clinic of Child and Adolescent Neuropsychiatry at the Second University of Naples, to the Department of Psychiatry at the "Magna Graecia" of Catanzaro University and to the Child Neuropsychiatry of the Department of Psychology at the University of Palermo from January 2012 to September 2013.

The diagnosis of NF1 was made according to the clinical criteria, established by the National Institutes of Health consensus in $1987^{18,19}$ and the reassessed version of $1997 .^{20}$

The control group was composed of 405 typically developing controls ( 207 boys, 198 girls; mean age $8.54 \pm 2.47$ years) recruited from schools in the Campania and Umbria regions of Italy. Subjects of both groups were recruited from the same urban area, and were all of Caucasian origin and of middle socioeconomic status (within class 2 or class 3 , corresponding to $€ 28,000-€ 55,000 /$ year and $€ 55,000-€ 75,000 /$ year, respectively, according to current Italian economic parameters), as previously reported. ${ }^{21}$

For both populations, the exclusion criteria were the following: allergies; endocrinological problems (eg, diabetes); preterm birth; ;2,23 epilepsy; psychiatric symptoms (such as attention deficit hyperactivity disorder, depression, and behavioral problems); mental retardation (IQ $\leq 70)$; previous rehabilitative treatment; ${ }^{24}$ borderline intellectual functioning (IQ ranging from 71-84); $;^{25,26}$ overweight (body mass index $[\mathrm{BMI}] \geq 85$ th percentile) or obesity (BMI $\geq 95$ th percentile); ${ }^{27,28}$ sleep disorders; ${ }^{29-34}$ primary nocturnal enuresis, ${ }^{35-37}$ and psychoactive drug administration. ${ }^{38,39}$

All parents gave their written informed consent. The Clinical Departmental University Ethics Committee at the Second University of Naples approved the study protocol, and the study was conducted according to the criteria of the Declaration of Helsinki as modified in $2000 .{ }^{40}$

\section{Parenting Stress Index-Short Form (PSI-SF)}

To assess the perceived stress in mothers of children with NF1, the Italian version of the PSI-SF was used.$^{41}$ The PSI-SF is a standardized tool that yields scores for parental stress across four areas via Parental Distress and Parent-Child Dysfunctional Interaction domains and Difficult Child and Total Stress subscales. It has 36 items and provides both raw and percentile scores. Each item is graded on a five-point Likert scale, from 1 (strongly disagree) to 5 (strongly agree).

The Parental Distress domain measures the distress that parents feel about their parenting role in light of other personal stresses, and has a cut-off score of 36; the Parent-Child Dysfunctional Interaction domain focuses on the perception of the child as not responsive to parental expectations, and has a cut-off score of 27; and the Difficult Child subscale represents behaviors that children often engage in that may make parenting easier or more difficult, and has a cut-off score of 36 .

The PSI-SF also produces a Defensive Responding subscale score, which indicates likely response bias. The subscale scores range from 12 to 60 , and the Total Stress subscale scores ranges from 36 to 180 , with higher scores indicating greater levels of parental stress. Thus, responses higher than the 85th percentile (one standard deviation above the mean) are interpreted as "clinically significant" for high levels of family stress. ${ }^{41}$

The PSI-SF has been used widely, and psychometric evidence supports its reliability and validity. ${ }^{37,38}$ The PSI-SF shows high internal consistency (Cronbach's alpha 0.92), and its validity has been established in parents of children with chronic medical conditions, including diabetes and asthma. ${ }^{42-44}$ In this study, the PSI-SF was administered only to the mother, being the parent assumed to usually spend more time with the children. 


\section{Statistical analysis}

The $t$-test and chi-square test were applied as appropriate to compare the characteristics (age, gender and BMI adjusted for age) and the PSI-SF results between the two populations. $P$-values $<0.05$ were considered to be statistically significant.

All data were coded and analyzed using the commercially available STATISTICA package for Windows (v 6.0; StatSoft Inc, Tulsa, OK, USA).

\section{Results}

The two study groups were comparable for age $(P=0.116)$, gender ( $P=0.886)$, and BMI adjusted for age $(P=0.305)$, as shown in Table 1.

Mothers of children affected by NF1 reported higher mean PSI-SF scores on the Parental Distress domain $(P<0.001)$, Difficult Child subscale $(P<0.001)$, and Total Stress subscale score $(P<0.001)$ than the mothers of typically developing children, as shown in Table 2.

No relevant differences between the two groups were found for the Parent-Child Dysfunctional Interaction domain $(P=0.566)$ or Defensive Responding domain scores $(P=0.160)$ (Table 2).

\section{Discussion}

The main finding of the present study was that there were higher stress levels in mothers of children affected by NF1 compared with mothers of healthy children $(33.19 \pm 11.02 \mathrm{vs}$ 26.94 $\pm 5.44 ; P<0.001)$ and in the Difficult Child subscale (26.14 \pm 5.03 vs $22.96 \pm 3.19 ; P<0.001$ ), even though their scores did not fall within the pathological ranges.

To interpret and understand these findings correctly, we could speculate that, while NF1 is an autosomal dominant condition, one half of all cases are thought to represent de novo mutations, with clinical characteristics that are often frightening for parents and unpredictable symptom progression. ${ }^{11}$ In this light, our results about the higher quote of the parental stress total level and in the Difficult Child subscale may be interpreted.

Table I Age, gender and z-score Body Mass Index (z-BMI) differences between children affected by neurofibromatosis I (NFI) and typically developing children (controls)

\begin{tabular}{llll}
\hline & NFI $(\mathbf{N}=\mathbf{3 7})$ & Controls $(\mathbf{N}=405)$ & $P$ \\
\hline Age, years & $7.86 \pm 2.94$ & $8.54 \pm 2.47$ & 0.116 \\
Gender (M/F) & $19 / 18$ & $207 / 198$ & 0.886 \\
z-BMI & $0.56 \pm 0.19$ & $0.52 \pm 0.23$ & 0.305 \\
\hline
\end{tabular}

Notes: Data are expressed as mean \pm standard deviation or number. The $t$-test and chi-square test, where appropriate, were applied. $P$-values $<0.05$ were considered statistically significant.
Table 2 Differences in PSI-SF ${ }^{42}$ domain scores between mothers of children with NFI and mothers of normal healthy controls

\begin{tabular}{llll}
\hline PSI-SF domains & $\mathbf{N F I}(\mathbf{N}=\mathbf{3 7})$ & Controls $(\mathbf{N}=405)$ & $\boldsymbol{P}$ \\
\hline PD & $33.19 \pm I I .02$ & $26.94 \pm 5.44$ & $<0.00 \mathrm{I}$ \\
PCDI & $21.86 \pm 4.91$ & $22.18 \pm 3.05$ & 0.566 \\
DC & $26.14 \pm 5.03$ & $22.96 \pm 3.19$ & $<0.00 \mathrm{I}$ \\
DEF & $12.93 \pm 5.04$ & $13.96 \pm 4.19$ & 0.160 \\
TS & $84.53 \pm 6.09$ & $65.27 \pm 4.39$ & $<0.00 \mathrm{I}$ \\
\hline
\end{tabular}

Notes: Data are expressed as mean \pm standard deviation. The $t$-test was applied. $P$-values $<0.05$ were considered statistically significant.

Abbreviations: PSI-SF, Parenting Stress Index-Short Form; PD, Parental Distress; PCDI, Parent-Child Dysfunctional Interaction; DC, Difficult Child; DEF, Defensive Responding; TS, Total Stress.

NF1 is an extremely variable condition, the morbidity and mortality of which is largely dictated by complications that are numerous and can involve any body system; ;,4,45 the stress of mothers of NF1 children may be interpreted as linked to the varied comorbidities of the illness. Moreover, the prognosis of NF1 remains unpredictable, with the possibility of complications affecting various organs, such as central nervous system cancer that can also involve the PTEN gene functions, even if not exclusively. ${ }^{46-48}$

NF1 affects all aspects of a child's life, because it is associated with cognitive impairment, learning disabilities, and neuropsychological deficits; ${ }^{49-55}$ sleep alterations; and hyperactivity. ${ }^{56} \mathrm{NF} 1$ also contributes to parental distress and affects family functioning, ${ }^{57,58}$ both of which could be influenced by parents' consideration of the child as "different" from other children, even if in an undefined way.

We could speculate that the high stress levels identified in mothers of NF1 children could be due not only to the specific characteristic of the NF1, that can be physically disfiguring, but also to the frequent clinical hospital controls, as with other chronic illness (eg, diabetes, asthma, primary ciliary dyskinesia, cystic fibrosis, migraine, and celiac disease). ${ }^{17,59-63}$ Specifically, parents of children affected by other genetic chronic illnesses seem to experience higher stress levels and greater burdens than parents of healthy children, yet parenting behavior and family functioning have been found to be quite similar to those of healthy control groups. ${ }^{61,62}$

In general, we can assume that, when a child is diagnosed with a chronic, life-threatening illness, there is a significant impact on the other family members, and the stress of parenting tends to reflect the level of stress/difficulty present in the parent-child relationship, including stress attributable to parental distress, difficult child characteristics, and dysfunctional parent-child interactions. Notably, research conducted by Hung et al in $2004^{64}$ suggested that different illnesses may 
result in different levels of stress of parenting, ie parenting of children affected by chronic illness can be a stressful condition in itself, becoming a vicious circle.

Conflict over child care responsibilities and decisionmaking are the most commonly reported stresses experienced by parents caring for children with a chronic illness. ${ }^{65-67}$ In 2010, Hullmann et al reported that parents of children with asthma who experience strained interactions with their child or are highly critical of their children are less likely to engage in effective disease management strategies and have children with more severe asthma. ${ }^{68}$ Therefore, these studies suggest that children's health outcomes are related to how well their parents function and adhere to the prescribed regimen. This seems to be particularly important for parents of children with cystic fibrosis, diabetes, and asthma, as most of the daily treatments are performed by parents. ${ }^{68}$

The toll that NF1 takes on families may be identified also in the oncologic potential of NF1 leads per se, linked to the role of neurofibromin protein as a tumor-suppressor gene and inhibitor of the Ras/mitogen-activated protein kinase pathway that is an important regulator of cellular growth and differentiation, aiding the dephosphorylation of ras guanosine triphosphate. ${ }^{69}$ In this perspective, the high maternal stress levels, expressed as difficult child perception (26.14 \pm 5.03 of NF1 mothers versus $22.96 \pm 3.19$ of mothers of comparisons, $P<0.001$ ), could also represent as the effect of the fear for life-threatening complications, such as cancer.

On the other hand, we have to clarify that the higher stress levels in mothers of NF1 children respect of mother of comparisons were not in the pathological range. In this light, these findings suggest that psychological support for parents with children affected by NF1 could help to prevent the developing of clinically evident difficulties in parentchild interactions that could further worsen the quality of life of children affected by NF1.

We should take into account some limitations of this study: 1) our data were derived from a small group affected by NF1 from a specific region of southern Italy; and 2) the assessment of parental stress levels was undertaken only in the mothers.

Notwithstanding these limitations, this could be considered a first report about parental stress evaluation in NF1, which is a multisystemic and complex disease with many still unrecognized features in pediatric patients and in their families. Our findings about the higher levels of maternal stress highlight the importance of considering the environmental aspects of NF1 management in developmental age, and suggest that specific psychological support could be of benefit to pediatric NF1 patients and their families.

\section{Disclosure}

The authors report no conflicts of interest in this work.

\section{References}

1. Sarnat HB, Flores-Sarnat L. Genetics of neural crest and neurocutaneous syndromes. Handb Clin Neurol. 2013;111:309-314.

2. OMIM. Online Mendelian Inheritance in Men. McKusick catalog of human genes. [webpage on the Internet]. Baltimore, MD: Johns Hopkins University Press; 2004. Available from: http://www.omim.org/ entry/162200.

3. Hughes RA, Huson SM, editors. The Neurofibromatoses: A Pathogenetic and Clinical Overview. London: Chapman and Hall Medical; 1994.

4. Friedman JM, Gutmann DH, MacCollin MD, Riccardi VM, editors. Neurofibromatosis: Phenotype, Natural History, and Pathogenesis. Baltimore, MD: Johns Hopkins University Press; 1999.

5. Upadhyaya M, Cooper DM, editors. Neurofibromatosis Type 1: From Genotype to Phenotype. Oxford: Bios Scientific; 1998.

6. Ashwal S, Rust R. Child neurology in the 20th century. Pediatr Res. 2003;53:345-361.

7. Ruggieri M. The different forms of neurofibromatosis. Childs Nerv Syst. 1999;15:295-308.

8. Hughes RA. Neurological complications of neurofibromatosis type 1. In: Hughes RA, Huson SM, editors. The Neurofibromatoses: A Pathogenetic and Clinical Overview. London: Chapman and Hall Medical; 1994:204-232.

9. Créange A, Zeller J, Rostaing-Rigattieri S, et al. Neurological complications of neurofibromatosis type 1 in adulthood. Brain. 1999;122:473-481.

10. Carotenuto M, Esposito M. Nutraceuticals safety and efficacy in migraine without aura in a population of children affected by neurofibromatosis type I. Neurol Sci. 2013;34(11):1905-1909.

11. Ablon J. Parents' responses to their child's diagnosis of neurofibromatosis 1. Am J Med Genet. 2000;93(2):136-142.

12. Glasscoe CA, Quittner AL. Psychological interventions for people with cystic fibrosis and their families. Cochrane Database Syst Rev. 2008:16;(3):CD003148.

13. Esposito M, Gallai B, Parisi L, et al. Maternal stress and childhood migraine: a new perspective on management. Neuropsychiatr Dis Treat. 2013;9:351-355.

14. Veale BM. Meeting the challenge of chronic illness in general practice. Med J Aust. 2003;179:247-249.

15. Eddy ME, Carter BD, Kronenberger WG, et al. Parent relationships and compliance in cystic fibrosis. J Pediatr Health Care. 1998;12(4): 196-202.

16. Spieth LE, Stark LJ, Mitchell MJ, et al. Observational assessment of family functioning at mealtime in preschool children with cystic fibrosis. J Pediatr Psychol. 2001;26(4):215-224.

17. Carotenuto M, Esposito M, Di Pasquale F, De Stefano S, Santamaria F. Psychological, cognitive and maternal stress assessment in children with primary ciliary dyskinesia. World $J$ Pediatr. 2013;9(4):312-317.

18. [No authors listed]. Neurofibromatosis. Conference statement. National Institutes of Health Consensus Development Conference. Arch Neurol. 1998;45:575-578.

19. Hachon C, Iannuzzi S, Chaix Y. Behavioural and cognitive phenotypes in children with neurofibromatosis type 1 (NF1): the link with the neurobiological level. Brain Dev. 2011;33(1):52-61.

20. Gutmann DH, Aylsworth A, Carey JC, et al. The diagnostic evaluation and multidisciplinary management of neurofibromatosis 1 and neurofibromatosis 2. JAMA. 1997;278(1):51-57. 
21. Esposito M, Verrotti A, Gimigliano F, et al. Motor coordination impairment and migraine in children: a new comorbidity? Eur J Pediatr. 2012;171(11):1599-1604.

22. Guzzetta A, Pizzardi A, Belmonti V, et al. Hand movements at 3 months predict later hemiplegia in term infants with neonatal cerebral infarction. Dev Med Child Neurol. 2010;52(8):767-772.

23. Guzzetta A, D'Acunto MG, Carotenuto M, et al. The effects of preterm infant massage on brain electrical activity. Dev Med Child Neurol. 2011;53 Suppl 4:46-51.

24. Esposito M, Gimigliano F, Ruberto M, et al. Psychomotor approach in children affected by nonretentive fecal soiling (FNRFS): a new rehabilitative purpose. Neuropsychiatr Dis Treat. 2013;9: 1433-1441.

25. Esposito M, Carotenuto M. Intellectual disabilities and power spectra analysis during sleep: a new perspective on borderline intellectual functioning. J Intellect Disabil Res. 2013. doi: 10.1111/jir.12036. In press.

26. Esposito M, Carotenuto M. Borderline intellectual functioning and sleep: the role of cyclic alternating pattern. Neurosci Lett. 2010;19;485(2):89-93.

27. Carotenuto M, Santoro N, Grandone A, et al. The insulin gene variable number of tandemrepeats (INS VNTR) genotype and sleep disordered breathing in childhood obesity. J Endocrinol Invest. 2009;32(9): $752-755$.

28. Carotenuto M, Bruni O, Santoro N, Del Giudice EM, Perrone L, Pascotto A. Waist circumference predicts the occurrence of sleepdisordered breathing in obese children and adolescents: a questionnairebased study. Sleep Med. 2006;7(4):357-361.

29. Carotenuto M, Guidetti V, Ruju F, Galli F, Tagliente FR, Pascotto A Headache disorders as risk factors for sleep disturbances in school aged children. J Headache Pain. 2005;6(4):268-270.

30. Esposito M, Parisi P, Miano S, Carotenuto M. Migraine and periodic limb movement disorders in sleep in children: a preliminary case-control study. J Headache Pain. 2013;14(1):57.

31. Carotenuto M, Gallai B, Parisi L, Roccella M, Esposito M. Acupressure therapy for insomnia in adolescents: a polysomnographic study. Neuropsychiatr Dis Treat. 2013;9:157-162.

32. Carotenuto M, Gimigliano F, Fiordelisi G, Ruberto M, Esposito M. Positional abnormalities during sleep in children affected by obstructive sleep apnea syndrome: The putative role of kinetic muscular chains. Med Hypotheses. 2013;81(2):306-308.

33. Carotenuto M, Esposito M, Parisi L, et al. Depressive symptoms and childhood sleep apnea syndrome. Neuropsychiatr Dis Treat. 2012;8: 369-373.

34. Carotenuto M, Esposito M, Pascotto A. Facial patterns and primary nocturnal enuresis in children. Sleep Breath. 2011;15(2):221-227.

35. Esposito M, Gallai B, Parisi L, et al. Primary nocturnal enuresis as a risk factor for sleep disorders: an observational questionnaire-based multicenter study. Neuropsychiatr Dis Treat. 2013;9:437-443.

36. Esposito M, Carotenuto M, Roccella M. Primary nocturnal enuresis and learning disability. Minerva Pediatr. 2011;63(2):99-104.

37. Esposito M, Gallai B, Parisi L, et al. Visuomotor competencies and primary monosymptomatic nocturnal enuresis in prepubertal aged children. Neuropsychiatr Dis Treat. 2013;9:921-926.

38. Coppola G, Auricchio G, Federico R, Carotenuto M, Pascotto A Lamotrigine versus valproic acid as first-line monotherapy in newly diagnosed typical absence seizures: an open-label, randomized, parallelgroup study. Epilepsia. 2004;45(9):1049-1053.

39. Coppola G, Licciardi F, Sciscio N, et al. Lamotrigine as first-line drug in childhood absence epilepsy: a clinical and neurophysiological study. Brain Dev. 2004;26(1):26-29.

40. WMA Declaration of Helsinki - Ethical Principles for Medical Research Involving Human Subjects [webpage on the Internet]. Ferney-Voltaire: World Medical Association; 1964 [amended 1975-2013]. Available from: http://www.wma.net/en/30publications/10policies/b3/. Accessed August 5, 2013.

41. Abidin RR. Parenting Stress Index, Third Edition: Professional Manual. Lutz, FL: Psychological Assessment Resources Inc; 1995.
42. Abdin RR. Parenting Stress Index-Short Form Manual. Los Angeles, CA: Western Psychological Services; 1990.

43. Carson DK, Schauer RW. Mothers of children with asthma: perceptions of parenting stress and the mother-child relationship. Psychol Rep. 1992;71:1139-1148.

44. Wysocki T, Huxtable K, Linscheid TR, Wayne W. Adjustment to diabetes mellitus in preschoolers and their mothers. Diabetes Care. $1989 ; 12: 524-529$.

45. Cnossen MH, Moons KG, Garssen MP, et al. Minor disease features in neurofibromatosis type 1 (NF1) and their possible value in diagnosis of NF1 children $<$ or $=6$ years and clinically suspected of having NF1. Neurofibromatosis team of Sophia Children's Hospital. J Med Genet. 1998;35:624-627.

46. Banerjee S, Crouse NR, Emnett RJ, Gianino SM, Gutmann DH. Neurofibromatosis-1 regulates mTOR-mediated astrocyte growth and glioma formation in a TSC/Rheb-independent manner. Proc Natl Acad Sci U S A. 2011;108(38):15996-16001.

47. Tada K, Kochi M, Saya H, et al. Preliminary observations on genetic alterations in pilocytic astrocytomas associated with neurofibromatosis 1 . Neuro Oncol. 2003;5(4):228-234.

48. Elia M, Amato C, Bottitta M, et al. An atypical patient with Cowden syndrome and PTEN gene mutation presenting with cortical malformation and focal epilepsy. Brain Dev. 2012;34(10):873-876.

49. Riccardi VM, Eichner JE, editors. Neurofibromatosis: Phenotype, Natural History, and Pathogenesis. London : Johns Hopkins University Press; 1986

50. Violante IR, Ribeiro MJ, Cunha G, et al. Abnormal brain activation in neurofibromatosis type 1: a link between visual processing and the default mode network. PLoS One. 2012;7(6):e38785.

51. Mautner VF, Kluwe L, Thakker SD, Leark RA. Treatment of ADHD in neurofibromatosis type 1. Dev Med Child Neurol. 2002;44:164-170.

52. Hyman SL, Arthur Shores E, North KN. Learning disabilities in children with neurofibromatosis type 1: subtypes, cognitive profile, and attention-deficit-hyperactivity disorder. Dev Med Child Neurol. 2006;48:973-977.

53. Friedman JM, Birch P, Greene C. National Neurofibromatosis Foundation International Database. Am J Med Genet. 1993;45:88-91.

54. North K. Neurofibromatosis type 1. Am J Med Genet. 2000;97: 119-127.

55. Levine TM, Materek A, Abel J, O’Donnell M, Cutting LE. Cognitive profile of neurofibromatosis type 1. Semin Pediatr Neurol. 2006;13: $8-20$.

56. Johnson H, Wiggs L, Stores G, Huson SM. Psychological disturbance and sleep disorders in children with neurofibromatosis type 1. Dev Med Child Neurol. 2005;47(4):237-242.

57. Reiter-Purtill J, Schorry EK, Lovell AM, Vannatta K, Gerhardt CA, Noll RB. Parental distress, family functioning, and social support in families with and without a child with neurofibromatosis 1 . J Pediatr Psychol. 2008;33(4):422-434.

58. Noll RB, Reiter-Purtill J, Moore BD, et al. Social, emotional, and behavioural functioning of children with NF1. Am J Med Genet A. 2007;143A(19):2261-2273.

59. Koinis-Mitchell D, McQuaid EL, Seifer R, et al. Symptom perception in children with asthma: cognitive and psychological factors. Health Psychol. 2009;28(2):226-237.

60. McCrimmon RJ, Ryan CM, Frier BM. Diabetes and cognitive dysfunction. Lancet. 2012;379(9833):2291-2299.

61. Ievers CE, Drotar D. Family and parental functioning in cystic fibrosis. $J$ Dev Behav Pediatr. 1996;17(1):48-55.

62. Walker LS, Ford MB, Donald WD. Cystic fibrosis and family stress: effects of age and severity of illness. Pediatrics. 1987;79(2):239-246.

63. Di Filippo T, Orlando MF, Concialdi G, et al. The quality of life in developing age children with celiac disease. Minerva Pediatr. 2013;65(6):599-608.

64. Hung JW, Wu YH, Yeh $\mathrm{CH}$. Comparing stress levels of parents of children with cancer and parents of children with physical disabilities. Psychooncology. 2004;13:898-903. 
65. Taanila A, Kokkonen J, Järvelin MR. The long-term effects of children's early-onset disability on marital relationships. Dev Med Child Neurol. 1996;38:567-577.

66. Quittner AL, Opipari LC, Espelage DL, Carter B, Eid N, Eigen H. Role strain in couples with and without a child with a chronic illness: associations with marital satisfaction, intimacy, and daily mood. Health Psychol. 1998;17:112-124.

67. Hodgkinson R, Lester H. Stresses and coping strategies of mothers living with a child with cystic fibrosis: implications for nursing professionals. J Adv Nurs. 2002;39(4):377-383.
68. Hullmann SE, Wolfe-Christensen C, Ryan JL, et al. Parental overprotection, perceived child vulnerability, and parenting stress: a cross-illness comparison. J Clin Psychol Med Settings. 2010;17(4): 357-365.

69. Jouhilahti EM, Peltonen S, Heape AM, Peltonen J. The pathoetiology of neurofibromatosis 1. Am J Pathol. 2011;178:1932-1939.

\section{Publish your work in this journal}

Neuropsychiatric Disease and Treatment is an international, peerreviewed journal of clinical therapeutics and pharmacology focusing on concise rapid reporting of clinical or pre-clinical studies on a range of neuropsychiatric and neurological disorders. This journal is indexed on PubMed Central, the 'PsycINFO' database and CAS.
The manuscript management system is completely online and includes a very quick and fair peer-review system, which is all easy to use. Visit http://www.dovepress.com/testimonials.php to read real quotes from published authors.

Submit your manuscript here: http://www.dovepress.com/neuropsychiatric-disease-and-treatment-journal 